\title{
Entrevista con Roger Chartier
}

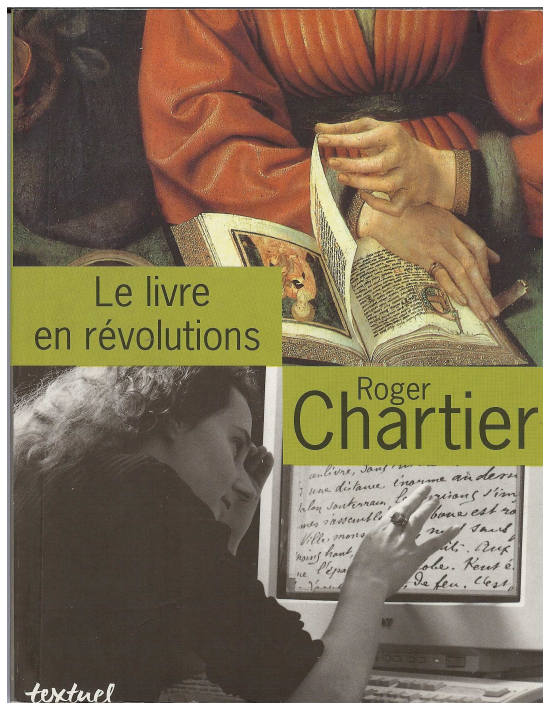

Las revoluciones del libro y la lectura: del códice al hipertexto.

\author{
MANUEL PEÑA DÍAZ \\ Universidad de Córdoba \\ España
}


Roger Chartier (Lyon, 1945) es director de estudios de la Escuela de Estudios Superiores en Ciencias Sociales (EHESS) de París y desde 2006 es profesor del Collège de France, en la cátedra «Écrit et cultures dans l'Europe moderne», además ha presidido Consejo Científico de la Biblioteca de Francia. Ha sido distinguido con la Annual Award de la American Printing History Association, 1990, el gran premio de historia (prix Gobert) de la Académie française en 1992, Doctor honoris causa de la Universidad Carlos III (Madrid) y Fellow de la British Academy, entre otros premios y reconocimientos.

Está considerado como uno de los más prestigiosos historiadores europeos. Su trabajo se ha centrado en la historia cultural e intelectual y, en particular, en el estudio de la articulación de lo escrito, el libro como objeto impreso y las prácticas de lectura. Fue responsable, junto a Henri-Jean Martin, de la dirección de la magna obra Histoire de l'édition française (Fayard, 1990-1991), así como del tercer volumen de la Historia de la vida privada (Taurus, 1989) dirigida por Georges Duby y Phillippe Ariès. Al castellano se han traducido la mayoría de sus obras, entre las que destacan El mundo como representación (Gedisa, 1992), Libros, lecturas y lectores en la Edad Moderna (Alianza, 1993), El orden de los libros: lectores, autores, bibliotecas en Europa entre los siglos XV y XVIII (Gedisa, 1994), Espacio público, crítica y desacralización: los orígenes culturales de la Revolución Francesa (Gedisa, 1995), Entre poder y placer. Cultura escrita y literatura en la Edad Moderna (Cátedra, 2000), Las revoluciones de la cultura escrita: Diálogo e intervenciones (Gedisa, 2000), Cultura escrita, literatura e historia. Conversaciones con Roger Chartier (FCE, 1999), Inscribir y borrar. Cultura escrita y literatura (siglos XI-XVIII) (Katz, 2006), Escuchar a los muertos con los ojos (Katz, 2008). Sin duda, la mejor síntesis de sus reflexiones sobre los interrogantes que atraviesan hoy en día la escritura de la historia, la historia cultural y la lectura como práctica se halla en el breve ensayo La historia o la lectura del tiempo (Gedisa, 2007). 
Nos encontramos con Roger Chartier en Grenoble, en el marco de un coloquio internacional sobre "Edición y Literatura en España", celebrado en la Universidad Stendhal Grenoble 3. Además de estar ante uno de los historiadores que más ha influido en la renovación de los Estudios Culturales a escala mundial, encontramos a un brillante a la vez que ameno conversador. Queremos que hable para Álabe acerca de uno de los principales focos de sus investigaciones: la lectura.

Usted ha destacado en sus estudios que es imprescindible distinguir entre las revoluciones del libro y las revoluciones de la lectura, ¿dónde hay que situar la invención de Gutenberg? ¿Y la irrupción de Internet?

Las revoluciones que transformaron la cultura escrita tienen diversas cronologías que no son sincrónicas. La invención de Gutenberg en el siglo XV revolucionó la modalidad de reproducción de los textos y la producción de los libros, pero no transformó la forma misma del libro ni, inmediatamente, las prácticas de lectura.

La invención del codex o códice (es decir del libro tal como lo conocemos todavía con sus hojas, páginas y encuadernación) sustituyó durante los primeros siglos de la era cristiana a la forma previa del "libro", es decir, a los rollos de los hebreos, griegos y romanos. Sin embargo, la aparición del códice no transformó la técnica de reproducción de los textos, siempre copiados a mano antes de Gutenberg.

Las sucesivas revoluciones de la lectura, que permitieron los progresos de la lectura silenciosa y visual, se iniciaron -en primer término- a lo largo de la Edad Media y se completó con la revolución de la lectura en el siglo XVIII, que se desarrolló en un marco de estabilidad morfológica y técnica. La originalidad de la revolución de nuestro presente reside en que asocia tres transformaciones radicales: propone una nueva técnica de composición, inscripción y comunicación de los textos, impone un nuevo soporte a los textos (la pantalla de los ordenadores cualesquiera que sean) e impone o surgiere nuevas maneras de leer: discontinuas, fragmentadas, segmentadas. No debemos menospreciar la singularidad de la revolución que nos hace entrar en el mundo digital. 
Bajo el imperio digital, ¿se puede hablar de una crisis de la cultura escrita? ¿Y de la lectura?

No sé. El diagnóstico me parece ambivalente. El mundo digital multiplica los usos de la escritura. Ofrece más facilidad para la composición de los textos, obliga a escribir en innumerables formularios, permite una comunicación inmediata, da acceso a una inmensa cantidad de textos. En esta perspectiva la crisis sería una crisis creada por la proliferación indomable e incontrolable de lo escrito, buscado, impuesto, multiplicado.

Pero se debe subrayar también que esta profusión textual constituye un profundo desafío para las categorías que nos definen como lectores, que no nacieron como lectores electrónicos. Estos caracteres de la cultura escrita se remiten a las nociones entrecruzadas de singularidad, originalidad y propiedad.

Los textos polifónicos, abiertos, móviles de la textualidad digital pueden interpretarse como una pérdida o una desaparición de las definiciones clásicas de lo que es un libro o una obra. En este sentido se puede pensar en una crisis de la lectura si se define la lectura como la respuesta de los lectores a un orden de lo escrito que supone autores individualizados, estabilidad de las obras y reconocimiento de la propiedad intelectual.

Es evidente, pues, que la revolución tecnológica actual ha transformado las relaciones entre el lector, el texto y el autor.

Para mí lo esencial reside en la transformación de la relación entre fragmentos y obra. Por cierto, no ha sido con la revolución digital cuando ha aparecido la lectura que fragmenta los textos y los transforma en lugares comunes (como en el Renacimiento), en antologías de extractos (como en el siglo XIX) o en libros de "textos escogidos" (como en las clases del siglo XIX o XX). Y no es la primera vez que una lectura discontinua puede elegir en un libro pasajes particulares. Pero en la cultura del codex la materialidad del libro imponía al lector una percepción, si no una lectura de la obra en su totalidad, coherencia, identidad. 
No sucede de ese modo con los textos digitales donde no es fácil, ni siquiera se espera que se establezca una relación entre el fragmento destacado por una lectura discontinua y la coherencia argumentativa, demostrativa o estética de la obra como tal.

El mundo digital aparece como un mundo de fragmentos destacados, desencuadernados. Se plantea así una alternativa fundamental entre la imposición de un nuevo orden de los discursos -concebido como una yuxtaposición de fragmentos recortados- 0 bien la posibilidad de introducir en el mundo digital los criterios e instrumentos capaces de conservar la antigua definición del libro, no tanto como objeto material, sino como discurso cuyo sentido está ubicado en la comprensión de su totalidad.

Los e-books, el periódico on-line, las enciclopedias virtuales, ¿cómo se puede valorar el impacto de este nuevo universo cultural sobre la propiedad intelectual y los intereses de la sociedad civil?

Debemos distinguir, pienso, entre las enciclopedias virtuales cuya estructura fragmentada encuentra en el mundo digital un soporte adecuado a una búsqueda rápida y una actualización inmediata, y los periódicos o libros cuya identidad propia está expresada por la composición de cada número y la coexistencia en el mismo soporte de varios textos reunidos por una misma intención autorial o editorial. Es a partir de semejante coexistencia textual cuando el lector puede percibir el proyecto intelectual, científico, ideológico o estético de una revista o de un periódico.

La contextualización puramente temática o enciclopédica de los artículos borra la percepción y comprensión de esa intención. Es el concepto mismo de libro electrónico o revista electrónica el que está amenazado por una técnica de inscripción de lo escrito. Esta técnica permite y favorece las lecturas temáticas destructoras de las lógicas narrativas, demostrativas o argumentativas, perceptibles por la secuencia de los capítulos o la yuxtaposición de las materias. 
Cambian los soportes, cambian los gestos... ¿han cambiado también las maneras de censurar o es un devenir de la nueva sociedad del control en la que nos hemos instaurado?

La posibilidad técnica de una comunicación libre, gratuita, universal e inmediata no borró la capacidad de censurar los contenidos y de control de la red por estados despóticos y tiránicos. Más allá de esta sombría observación debemos hacer hincapié, otra vez, en las ambivalencias o contradicciones de la nueva técnica. Si permite una construcción colectiva del saber, como si fuese una nueva República de las letras extendida a toda la humanidad, es verdad, también, que se asegura la proliferación de los errores, de las falsificaciones, de las propagandas. Éste es el desafío que debe afrontar, por ejemplo, la wikipedia. Por otra parte, la red promete una comunicación universal y la construcción de un espacio público y crítico en el cual, como escribió Kant, cada uno puede hacer un uso público de su razón. Es verdad. Pero también, como lo vemos con Facebook, siempre la privacidad está amenazada por la circulación y apropiación de los datos más privados que caracterizan a un individuo. Los miedos frente a Google se remiten a estos dos elementos: el temor de la transformación de los libros una vez digitalizados en un gigantesco mercado de "informaciones" extraídas de obras, y la reducción de estas obras al estatuto de bancos de datos. Son estos desafíos e incertidumbres los que nos obligan a una reflexión más rigurosa (y más histórica) sobre las contradicciones que atraviesan la cultura escrita hoy en día. 


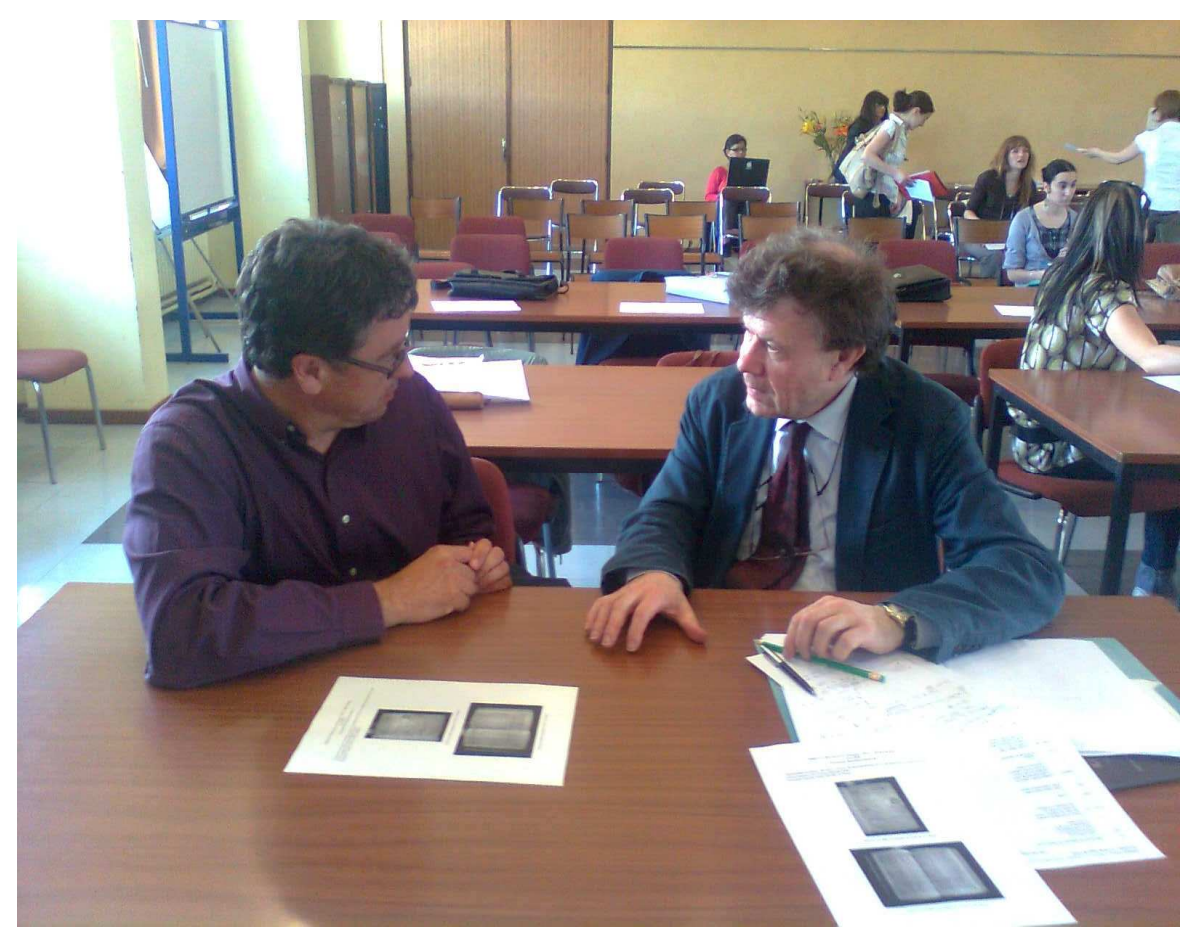

(Entrevista recibida: 18-06-2010; aceptada: 26-06-2010) 